\title{
Modular Protein Engineering Approach to the Functionalization of Gold Nanoparticles for Use in Clinical Diagnostics
}

\author{
Timothy Robson, ${ }^{\dagger}$ Deepan S. H. Shah, ${ }^{\dagger}$ Alexandra S. Solovyova, ${ }^{\dagger}$ and Jeremy H. Lakey* ${ }^{\dagger}$
}

†nstitute for Cell and Molecular Biosciences, The Medical School, Newcastle University, Framlington Place, Newcastle upon Tyne NE2 4HH, U.K.

${ }^{\ddagger}$ Orla Protein Technologies Ltd., Biosciences Centre, International Centre for Life, Times Square, Newcastle upon Tyne NE1 4EP, U.K.

\section{Supporting Information}

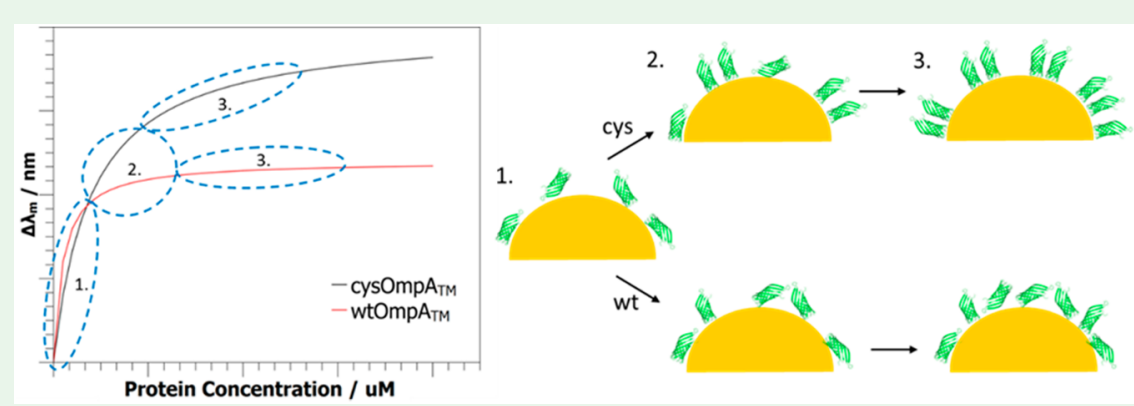

ABSTRACT: Functional protein-gold nanoparticle (AuNP) conjugates have a wide variety of applications including biosensing and drug delivery. Correct protein orientation, which is important to maintain functionality on the nanoparticle surface, can be difficult to achieve in practice, and dedicated protein scaffolds have been used on planar gold surfaces to drive the self-assembly of oriented protein arrays. Here we use the transmembrane domain of Escherichia coli outer membrane protein $\mathrm{A}\left(\mathrm{OmpA}_{\mathrm{TM}}\right)$ to create protein-AuNP conjugates. The addition of a single cysteine residue into a periplasmic loop, to create cysOmpA $\mathrm{A}_{\mathrm{TM}}$, drives oriented assembly and increased equilibrium binding. As the protein surface concentration increases, the sulfur-gold bond in cysOmpA $\mathrm{TM}_{\mathrm{TM}}$ creates a more densely populated AuNP surface than the poorly organized wtOmp $\mathrm{A}_{\mathrm{TM}}$ layer. The functionalization of AuNP improved both their stability and homogeneity. This was further exploited using multidomain protein chimeras, based on cysOmpA $\mathrm{TM}_{\mathrm{T}}$, which were shown to form ordered protein arrays with their functional domains displayed away from the AuNP surface. A fusion with protein $G$ was shown to specifically bind antibodies via their Fc region. Next, an in vitro selected single chain antibody ( $\mathrm{scFv}$ )-cysOmpA $\mathrm{A}_{\mathrm{TM}}$ fusion protein, bound to AuNP, detected influenza $\mathrm{A}$ nucleoprotein, a widely used antigen in diagnostic assays. Finally, using the same $s c F v-c y s O m p A_{T M}-A_{u N P}$ conjugates, a prototype lateral flow assay for influenza demonstrated the utility of fully recombinant self-assembling sensor layers. By simultaneously removing the need for both animal antibodies and a separate immobilization procedure, this technology could greatly simplify the development of a range of in vitro diagnostics.

KEYWORDS: gold nanoparticles, self-assembly, outer membrane proteins, single chain variable fragment, LSPR, lateral flow assay, biosensing

\section{INTRODUCTION}

The generation of functional AuNP-protein conjugates is of great interest and importance for many bioscience applications, particularly diagnostics and therapeutics. ${ }^{1,2}$ AuNPs are an attractive vehicle for biomolecules as they can be made in welldefined sizes, ${ }^{3}$ are biocompatible, ${ }^{4}$ and exhibit unique optical properties that provide an intrinsic ability to sense changes in the local environment ${ }^{5}$ and have also been utilized for

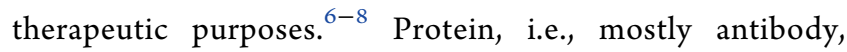
conjugation is generally used to bestow biological functionality to the AuNP surface, such as targeting of a particular protein or antigen of interest ${ }^{9,10}$ or carrying out therapeutic processes, including gene editing. ${ }^{11,12}$ Numerous protein attachment strategies have been developed, usually via chemically modified linker molecules that are assembled on the AuNP surface through terminal thiol groups. ${ }^{13}$ These linker chemistries can be quite widely applicable, such as coupling to amines or hydrazide coupling of antibody glycans. Furthermore, it has been shown that more directed coupling, providing orientational control, improves functionality of the protein-nanoparticle conjugates. ${ }^{9,10}$ Control over antibody orientation has been shown to enhance antigen binding when immobilized on planar surfaces. ${ }^{14}$ Previously, it has been shown that outer membrane $\beta$-barrel proteins from Escherichia coli can be

Received: $\quad$ May 4, 2018

Accepted: June 28, 2018

Published: June 28, 2018 
Scheme 1. Assembly of the Modular Protein System on the AuNP Surface and Binding of an Antigen in Solution

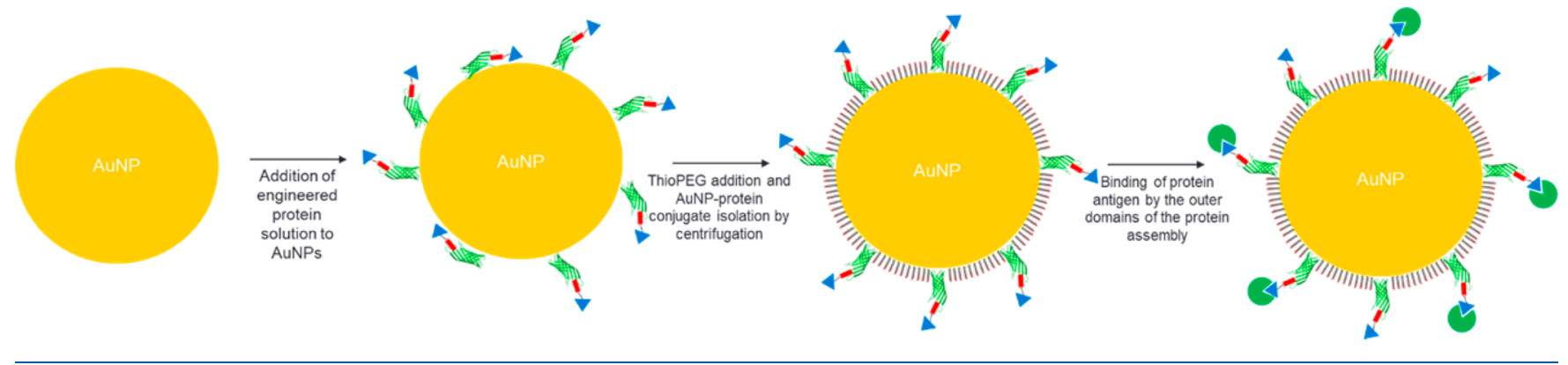

A

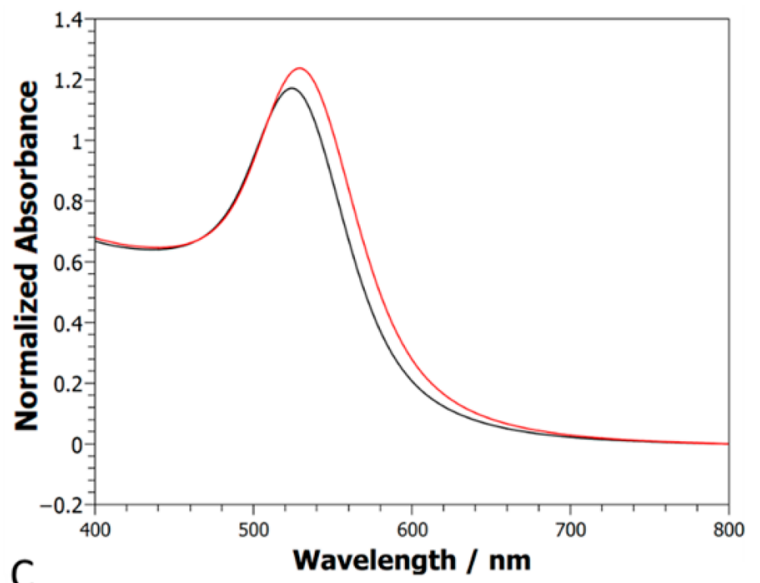

C

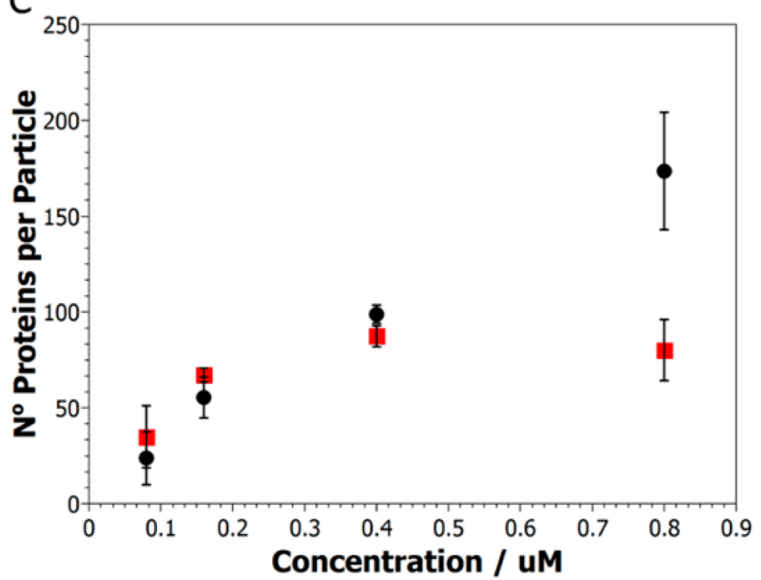

B

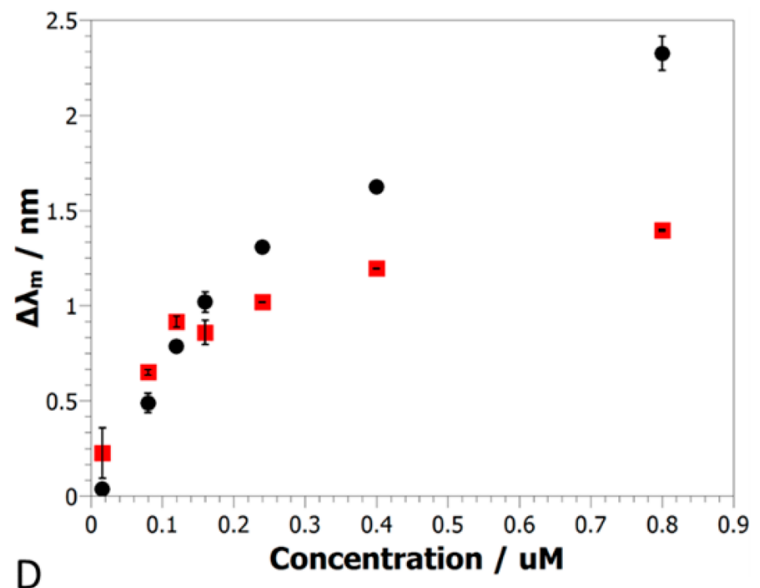

D

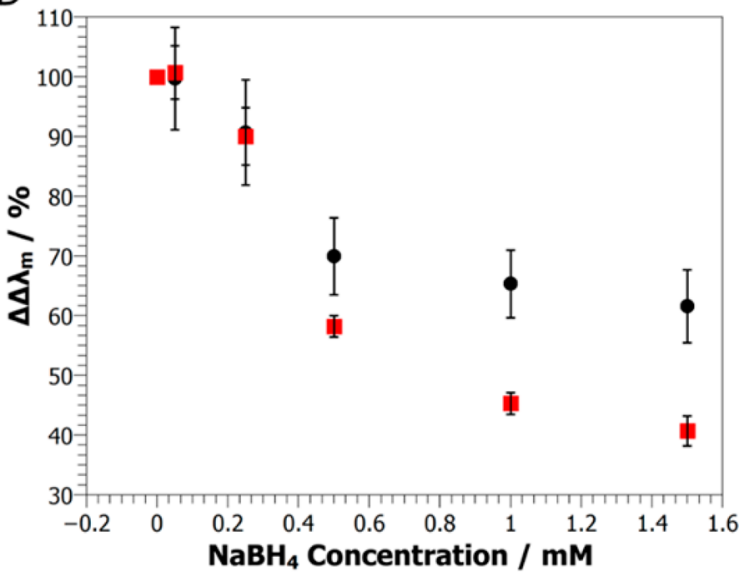

Figure 1. Binding and stability of wtOmpATM (red box) and cysOmpATM (๑) to $20 \mathrm{~nm}$ AuNPs. AuNPs at an OD $525 \mathrm{~nm}=1$ were mixed with protein at concentrations between 0.016 and $0.8 \mu \mathrm{M}$ before overnight incubation at room temperature. (A) Example spectra of AuNPs before (black line) and after (red line) overnight incubation with $0.8 \mu \mathrm{M}$ cysOmpATM showing the significant shift in the LSPR peak. (B) Shift in the LSPR barycentric mean wavelength $\left(\Delta \lambda_{\mathrm{m}}\right)$ after overnight equilibration. (C) Fluorescence spectroscopy results showing the average number of proteins bound to each AuNP with increasing protein concentration. The amount of protein binding was calculated by the reduction in soluble protein fluorescence signal caused by incubation with AuNPs and their subsequent removal along with bound protein. (D) Change in the LSPR $\Delta \lambda_{\mathrm{m}}$ of wtOmpA $\mathrm{TM}_{\mathrm{TM}}$ and cysOmpA $\mathrm{TM}_{\mathrm{TM}}-$ AuNP conjugates $\left(\Delta \Delta \lambda_{\mathrm{m}}\right)$ when challenged with increasing concentrations of $\mathrm{NaBH}_{4}$. Error bars represent the standard error of the mean based upon $N=3$.

engineered to self-assemble into oriented monolayers on planar gold surfaces. An upright orientation was driven by both the addition of a single cysteine residue into a periplasmic turn and coassembly with membrane mimicking thioAlkylPEG molecules. ${ }^{15,16}$ The transmembrane domain of $E$. coli outer membrane protein $\mathrm{A}\left(\mathrm{OmpA}_{\mathrm{TM}}\right)$ can be used as such a protein engineering scaffold protein when circularly permuted to enable modification of its extracellular loops. ${ }^{17}$ This allows heterologous functional domains, such as antibody binding domains from protein $A$ and protein $G,{ }^{18,19}$ to be fused to
$\mathrm{OmpA}_{\mathrm{TM}}$ and displayed away from the surface. The utility of such protein arrays on planar gold surfaces for biological sensing has been previously presented. ${ }^{20}$ AuNP-protein conjugates are widely used in diagnostic assays, particularly for lateral flow tests, where they are used to detect many different antigens, e.g., hormones and viral proteins. ${ }^{21}$ While protein binding to AuNPs has been extensively researched, most studies have focused on the stoichiometry and thermodynamics of globular model proteins such as serum albumins and ubiquitin. ${ }^{22-25}$ There are fewer examples of 

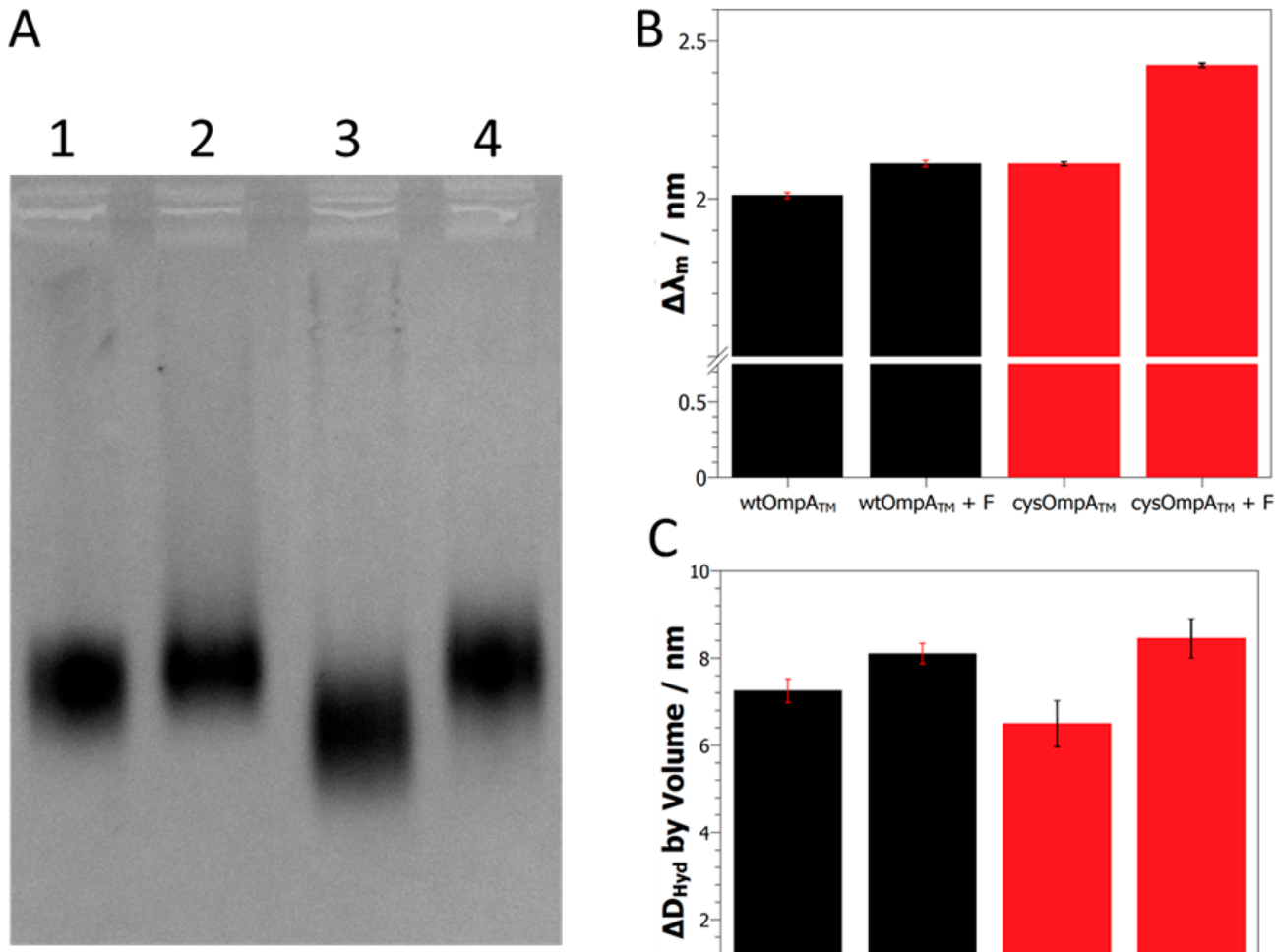

C

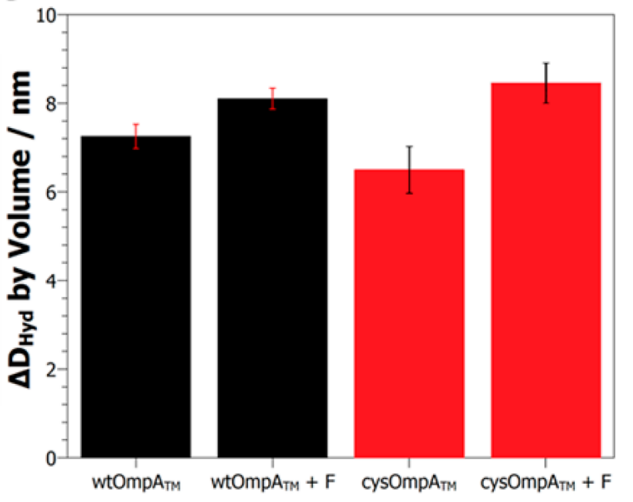

Figure 2. Characterization of AuNPs (preconjugated with wild type and cysOmpA $\mathrm{TM}_{\mathrm{TM}}$ ) before and after overnight thioAlkylPEG filler incubation. 20 $\mathrm{nm}$ AuNPs at $\mathrm{OD}_{525 \mathrm{~nm}}=10$ were incubated with $8 \mu \mathrm{M}$ of either protein for $30 \mathrm{~min}$, followed by coassembly with filler by mixing the proteinAuNP conjugates with $8 \mu \mathrm{M}$ filler and incubating overnight. (A) $0.5 \%$ agarose gel of wtOmpA $\mathrm{T}_{\mathrm{TM}}$ particles before (1) and after filler addition (2) and cysOmpA $\mathrm{T}_{\mathrm{TM}}$ particles before (3) and after (4) filler (F) addition. Corresponding LSPR absorbance peak barycentric mean wavelength $\Delta \lambda_{\mathrm{m}}(\mathrm{B})$ and change in hydrodynamic radius $\left(\Delta \mathrm{D}_{\mathrm{Hyd}}\right)$ measured by DLS (C) data (where $\Delta D_{\mathrm{Hyd}}=0$ corresponds to bare particles) for the same proteinAuNP conjugate samples used in (A). Error bars represent the standard error of the mean based upon three measurements.

control over protein orientation, with changes in AuNP surface charge $^{26}$ and site-directed insertion of cysteine residues ${ }^{27}$ being shown to influence $\alpha$-synuclein and E. coli PPase orientation on the AuNP surface, respectively. Here we present the selfassembly of engineered $\mathrm{OmpA}_{\mathrm{TM}}$ proteins on the surface of 20 $\mathrm{nm}$ AuNPs (Scheme 1). Protein binding could be sensitively monitored by observing changes in the localized surface plasmon resonance (LSPR) peak, and the protein layer structure was investigated by dynamic light scattering (DLS). Furthermore, we introduce chimeric, single chain antibody$\mathrm{OmpA}_{\mathrm{TM}}$ proteins as a simple method to functionalize AuNP conjugates to detect a clinical antigen, influenza $A$ nucleoprotein (FluA NP). NP is the preferred target for diagnostic assays due to its highly conserved nature and type specificity for type A and B influenza. ${ }^{20,28}$

\section{RESULTS AND DISCUSSION}

Cysteine Mediated Binding and Assembly of Om$\mathrm{pA}_{\mathrm{TM}}$. Initially we investigated the effect of a single cysteine residue, inserted into a periplasmic turn of $O \mathrm{mpA}_{\mathrm{TM}}$, on the binding of detergent solubilized $\mathrm{OmpA}_{\mathrm{TM}}$ to the surface of AuNPs. We present data exclusively for $20 \mathrm{~nm}$ diameter commercial, citrate stabilized AuNPs, but we have also successfully used the $10 \mathrm{~nm}$ version and even homemade AuNPs prepared by precipitation from $\mathrm{Au}_{2} \mathrm{Cl}_{6}$. The presence of a single cysteine per protein was confirmed by DNA sequencing of the cysOmpA $\mathrm{TM}_{\mathrm{TM}}$ gene and the cysteine reactivity after TCEP treatment has been confirmed previously. ${ }^{17}$
Protein binding was measured by the shift in the barycentric mean wavelength $\left(\Delta \lambda_{\mathrm{m}}\right)$ of the LSPR absorption peak. Higher equilibrium binding was observed for the cysOmp $\mathrm{A}_{\mathrm{TM}}$ mutant than for the wild type protein $\left(w t O m p A_{T M}\right)$, with an increase in the $\Delta \lambda_{\mathrm{m}}$ of $0.93 \mathrm{~nm}$ (Figure 1A). The increased binding was also observed by fluorescence spectroscopy experiments which recorded the reduction in concentration of free protein (Figure 1B). To confirm the formation of a sulfur-gold bond, the stabilities of the WT and cysOmpA $\mathrm{TM}_{\mathrm{TM}}$ protein-AuNP conjugates were probed by challenging the particles with borohydride ions $\left(\mathrm{BH}_{4}^{-}\right)$, which have a high affinity for the nanoparticle surface. ${ }^{29}$ This revealed a significant increase in the stability of the conjugated particles when the cysteine residue was present (Figure $1 \mathrm{C}$ ).

A stark difference between the two particle types was revealed by agarose gel electrophoresis where the cysOm$\mathrm{pA}_{\mathrm{TM}}-\mathrm{AuNP}$ conjugates migrate faster than the wild typeAuNP conjugates, indicating that they had an increased net negative charge $\left(\mathrm{OmpA}_{\mathrm{TM}}\right.$ has an estimated charge of -3.6 at $\mathrm{pH}$ 8) (Figure 2A). Characterization of these protein-AuNP conjugates by DLS showed that the diameters of the ${ }_{\text {wtOmpA }}$ TM and cysOmpA $\mathrm{TM}_{\mathrm{TM}}$ particles were remarkably similar; however the latter sample had a greater LSPR $\lambda_{\mathrm{m}}$ shift indicating greater protein binding (Figure $2 \mathrm{~B}$ and Figure 2C). The assembly for this experiment was carried out at a 10 times higher overall concentration of both protein and AuNP compared to Figure 1, and while the LSPR shifts for wtOmpA $_{\mathrm{TM}}$ increase from 1.4 to $2.0 \mathrm{~nm}$, the cysOmpA $\mathrm{A}_{\mathrm{TM}}$ 
A

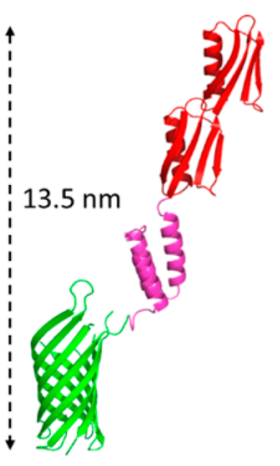

C

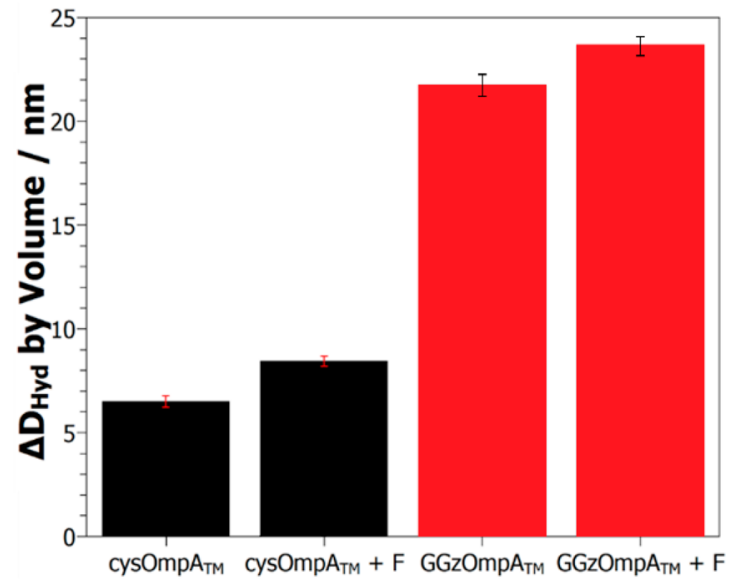

B

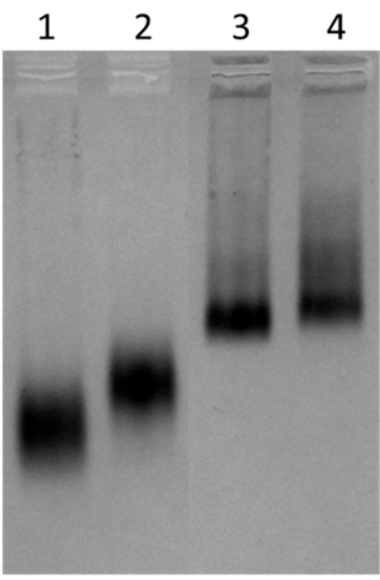

$\mathrm{E}$
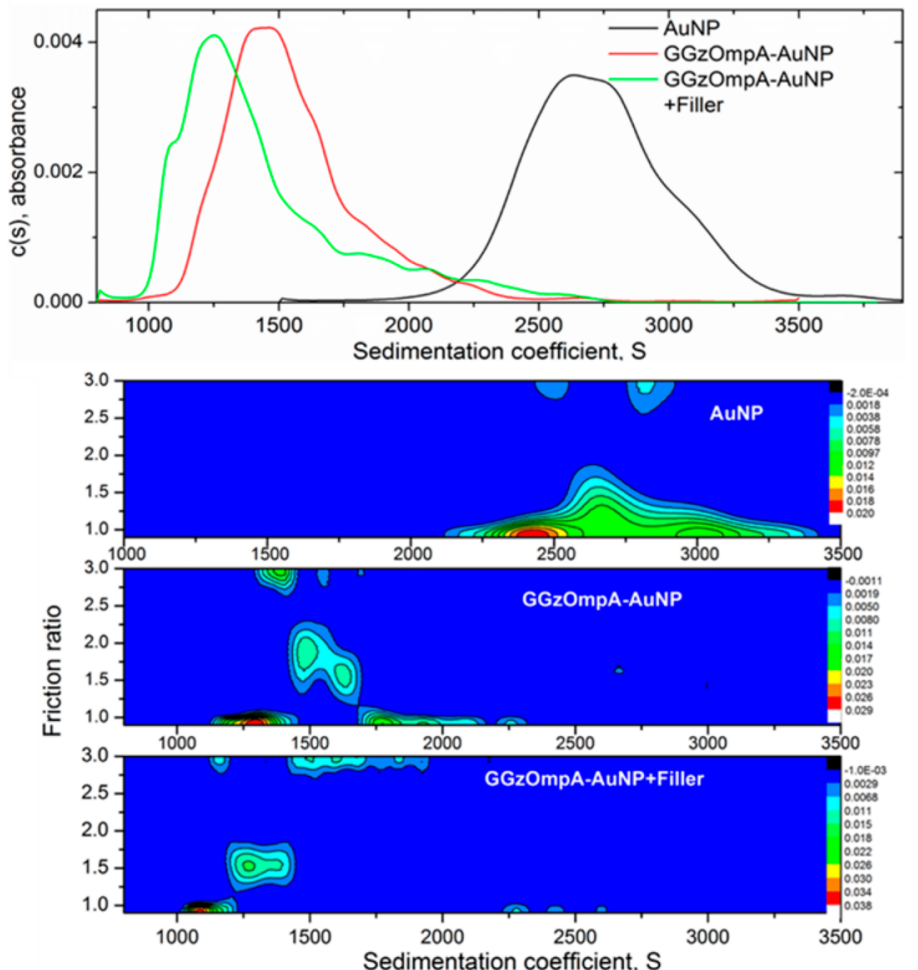

Figure 3. Characterization of $\mathrm{GGzOmpA}_{\mathrm{TM}}-\mathrm{AuNP}$ conjugates. (A) Cartoon of GGzOmpA $\mathrm{TM}_{\mathrm{TM}}$ which consists of tandem $\mathrm{B}$-domains (red) from protein $\mathrm{G}$ and a single $\mathrm{Z}$ domain from protein $\mathrm{A}$ (magenta) fused to the $\mathrm{N}$-terminus of a circularly permuted $\mathrm{Omp} \mathrm{A}_{\mathrm{TM}}$ domain (green). (B) $0.5 \%$ agarose gel comparing cysOmpA $\mathrm{TM}_{\mathrm{T}}$ coated particles, before (1) and after (2) filler addition, and $\mathrm{GGzOmpA}_{\mathrm{TM}}$ coated particles, before (3) and after (4) filler addition. (C) Corresponding DLS data for the agarose gel samples showing the increase in the hydrodynamic diameter $\left(\Delta D_{\mathrm{Hyd}}\right)$ of the particles (where $\Delta D_{\mathrm{Hyd}}=0$ corresponds to bare particles). (D) Representative negative stain TEM images of bare AuNPs (1) and GGzOmpA $\mathrm{TM}+$ filler conjugated AuNPs (2 and 3). Scale bar $=25 \mathrm{~nm}$. The protein coated AuNPs were prepared for TEM by excising the agarose gel band from lane 4 in (B) and extracting overnight in Nanopure $\mathrm{H}_{2} \mathrm{O}$. (E) AUC analysis of commercial $20 \mathrm{~nm}$ AuNPs before and after conjugation with $\mathrm{GGzOmpA}_{\mathrm{TM}}$ and filler. Both size (top) and size-and-shape (bottom) distributions of the particles are shown. The friction ratio corresponds to the symmetry of the particle with a value of 1 indicating a spherical particle.

values are 2.4 and 2.1 , respectively, confirming the apparent surface saturation observed at $0.8 \mu \mathrm{M}$ cysOmpA $_{\mathrm{TM}}$ and the less specific binding of the WT protein. Infilling of the nanoparticle surface with an uncharged lipid mimicking molecule, 1mercaptoundecyl-11 hexa(ethylene glycol) (filler), increased the size of both wild type and cysOmpA $\mathrm{TM}_{\mathrm{TM}}$ particles, as seen by DLS, and retarded the electrophoretic migration of the particles (Figure 2A and Figure 2C). The effect of filler addition on both the size of the particles and the increase in the $\Delta \lambda_{\mathrm{m}}$ was much more pronounced for the cysOmpA $\mathrm{A}_{\mathrm{TM}}$ particles. These results suggest that insertion of the cysteine residue plays a role in both protein binding and organized assembly of $\mathrm{OmpA}_{\mathrm{TM}}$ on the nanoparticle surface. Interestingly, the binding kinetics of the wild type and cysOmpA proteins were strikingly similar, with pseudo-second-order rate constants of $14.76 \pm 1.12$ and $14.86 \pm 1.09 \times 10^{-3} \mathrm{~s}^{-1} \mathrm{~nm}^{-1}$ respectively (Supporting Information). This would suggest that electrostatic interactions dominate the early stages of protein binding, i.e., in the seconds to minutes range, followed by reorganization of the protein layer to maximize the number of favorable interactions. Protein binding to AuNPs has been shown to obey equilibrium dynamics; ${ }^{23,25}$ therefore the formation of a thermodynamically stable thiol-gold bond between the protein and AuNP would shift the binding equilibrium toward associated and oriented protein. Outer membrane $\beta$-barrels consist of a hydrophobic core region, which normally resides in the lipid membrane, and hydrophilic loops at their periplasmic and extracellular ends. A standing orientation, driven by the location of the cysteine in a periplasmic loop, as shown by neutron scattering experiments on planar surfaces, ${ }^{17}$ maximizes favorable hydrophobic interactions with filler molecules and neighboring proteins while minimizing the surface footprint of bound proteins, thus increasing the maximum adsorption capacity of the nanoparticle surface. A more organized cysOmpA $\mathrm{T}_{\mathrm{TM}}$ array on the AuNP surface would explain the increase in the apparent 


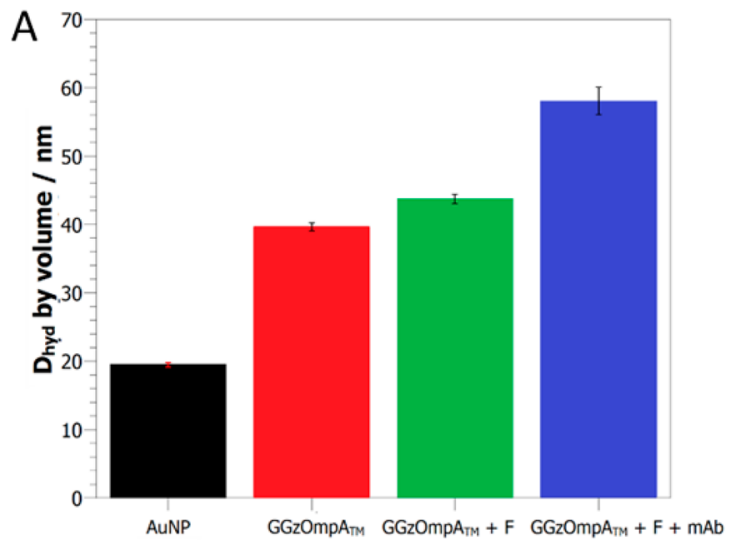

C1

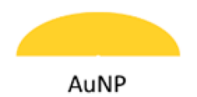

$\mathrm{GGZOMPATM}_{\mathrm{T}} \quad \mathrm{GGZOMPA_{ \textrm {TM } }}+\mathrm{F} \quad \mathrm{GGZOMPA}+\mathrm{F}+\mathrm{mAb}$

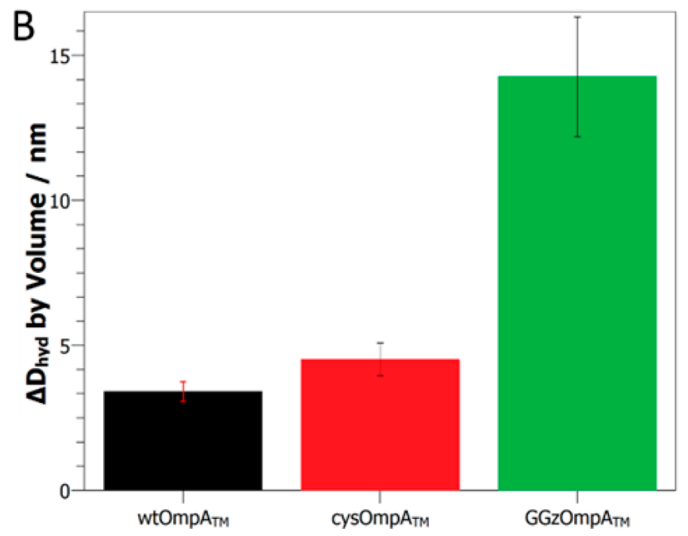

C2

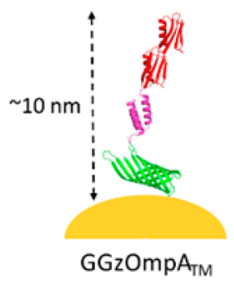

C4

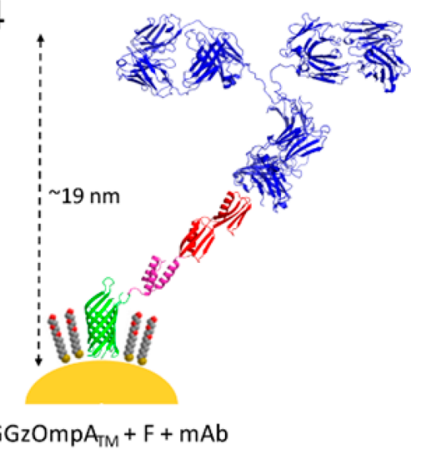

Figure 4. Assembly of GGzOmpA $\mathrm{TM}_{\mathrm{TM}}$ arrays on $20 \mathrm{~nm}$ AuNPs. (A) Hydrodynamic diameter $\left(D_{\text {hyd }}\right)$ of AuNPs measured by DLS showing changes in $D_{\text {hyd }}$ after sequential addition of GGzOmpA $\mathrm{TM}_{\mathrm{TM}}$, thioAlkylPEG filler $(\mathrm{F})$, and a monoclonal antibody $(\mathrm{mAb})$. (B) DLS data comparing change in the $D_{\text {hyd }}$ of GGzOmpA $\mathrm{TM}_{\mathrm{TM}}$ coated particles with wtOmpA $\mathrm{TM}_{\mathrm{TM}}$ and cysOmpA $\mathrm{T}_{\mathrm{TM}}$ control particles after incubation with a $\mathrm{mAb}$ (where $\Delta D_{\mathrm{Hyd}}=0$ corresponds to the value from protein coated particles). (C) Schematic representation of the protein layers after each step with the indicated layer thicknesses calculated from the changes in the $D_{\text {hyd }}$ reported in (A) and (B). Error bars represent the standard error of the mean based upon $N=3$.

protein binding and also the increased filler binding observed compared to a wtOmpA $\mathrm{T}_{\mathrm{TM}}$ array with poorly oriented proteins in many different conformations. The high wtOmpA binding is most likely due to exposed lysine resides, which have been shown to mediate binding to AuNP; ${ }^{30}$ in particular, residues K73 and R102 form a positively charged surface at the extracellular end of the barrel. The N-terminal 6xHis-tag may also play a role in AuNP binding. ${ }^{31}$ The protein binding behavior observed in this study is consistent with a protein binding model proposed by Wang et al., where initial association is dynamic and reversible, followed by reorganization of the protein layer to maximize the available AuNP surface and, finally, irreversible binding of the protein which is accelerated here by the exposed cysteine residue. ${ }^{25}$

Surface Assembly of Antibody Capture Domains. To test the utility of cysOmpA $\mathrm{TM}_{\mathrm{TM}}-\mathrm{AuNP}$ conjugates as a diagnostic tool, a multidomain version termed $\mathrm{GGzOmpA}_{\mathrm{TM}}$ was used. This protein combines tandem B-domains from protein $\mathrm{G}(\mathrm{GG})^{19}$ and a Z-domain from protein $\mathrm{A}(\mathrm{z})^{18}$ bound to the $\mathrm{N}$-terminus of a circularly permuted OmpA transmembrane domain $\left(\mathrm{OmpA}_{\mathrm{TM}}\right)^{20}$ and has a total length of approximately $135 \AA$ when standing on a gold surface ${ }^{20}$ (Figure $3 \mathrm{~A}$ ). Both $\mathrm{B}$ - and $\mathrm{Z}$-domains bind to the constant regions of immunoglobulin $\mathrm{G}$ ( $\mathrm{IgG}$ ) enabling oriented presentation of antibodies on surfaces so that their binding sites are exposed. As expected, gel electrophoresis and DLS measurements showed a greater increase in particle size on addition of $\mathrm{GGzOmpA}_{\mathrm{TM}}$ when compared with cysOmpA $\mathrm{TM}_{\mathrm{TM}}$ (Figure $3 \mathrm{~B}$ and Figure $3 \mathrm{C}$ ). Negative stained transmission electron microscopy images of $\mathrm{GGzOmpA}_{\mathrm{TM}}-\mathrm{AuNP}$ conjugates also revealed material bound to the surface that was not visible on untreated particles (Figure 3D). These features are too large to be individual $\mathrm{GGzOmpA}_{\mathrm{TM}}$ proteins and may be groups of closely associated proteins since at around $11 \mathrm{~nm}$ in length they are consistent with the height of $\mathrm{GGzOmpA}_{\mathrm{TM}}$. Further analysis of $\mathrm{GGzOmpA}_{\mathrm{TM}}$-AuNP conjugates was carried out using sedimentation velocity analytical ultracentrifugation. One-dimensional sedimentation coefficient, $c(s)$, distribution analysis ${ }^{32}$ showed broad single peaks for each sample (Figure 3E, top panel). The $c(s)$ distributions of the protein coated AuNPs were clearly affected by changes in their size and density when compared with the untreated AuNPs. More in-depth analysis using a two-dimensional "size and shape" distribution, ${ }^{33-35} c\left(s, f / f_{0}\right)$, demonstrated a higher fraction of aggregated, asymmetrical species (with a friction ratio significantly above 1) before addition of the filler molecule on to the AuNP surface (Figure 3E, bottom panel). This suggests that incorporation of filler molecules into the $\mathrm{GGzOmpA}_{\mathrm{TM}}$ layer results in a more ordered proteinfiller array. The resulting particles were more spherical in shape and had a lower level of inhomogeneity when compared with AuNPs coated in just $\mathrm{GGzOmpA}_{\mathrm{TM}}$ (more details in the Supporting Information). 

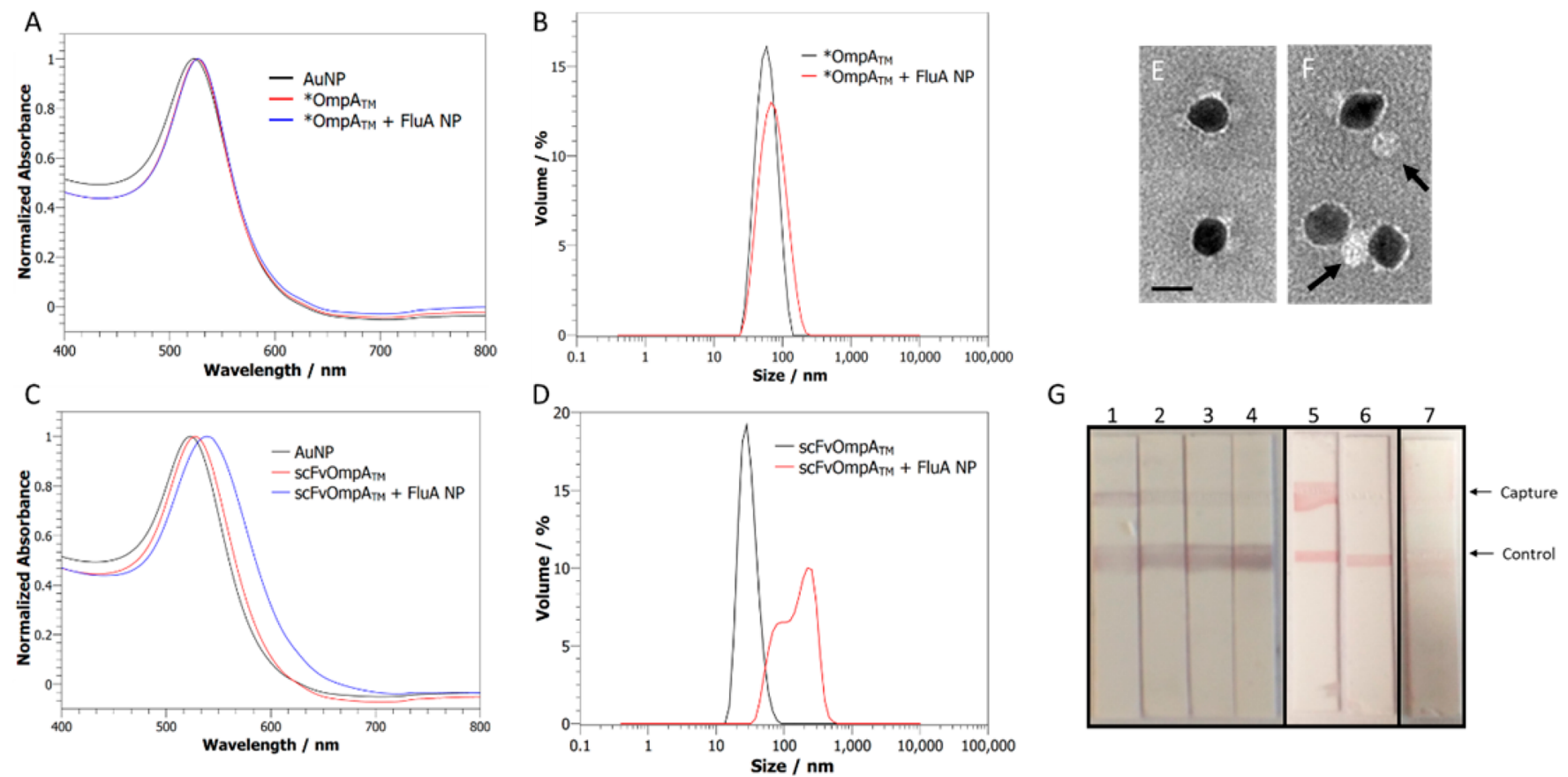

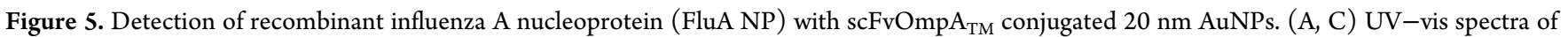
the assembly and subsequent incubation with FluA NP of the ${ }^{*} \mathrm{OmpA}_{\mathrm{TM}}$ control (helical linker) and $\mathrm{scFvOmpA_{ \textrm {TM } }}$ (linker plus variable heavy $V_{\mathrm{H}}$ and variable $V_{\mathrm{L}}$ light chains of IgG antibody) proteins on AuNPs. (B, D) Particle size distribution anaylsis of $* \mathrm{OmpA}_{\mathrm{TM}}$ and scFvOmpA conjugated particles before and after incubation with FluA NP. Representative negative stain TEM images of scFvOmpA $\mathrm{A}_{\mathrm{TM}} \mathrm{conjugated} \mathrm{AuNPs}$ before (E) and after (F) incubation with FluA NP. Bound FluA NP is indicated by the black arrows, and the scale bar is $25 \mathrm{~nm}$. (G) Lateral flow assay which used $\alpha$-FluA NP and $\alpha$-human IgG antibodies, as the capture and control lines, respectively. Strips $1-4$ correspond to scFvOmpA $\mathrm{TM}_{\mathrm{TM}}$ particles incubated with between 5000 and $500 \mathrm{ng} / \mathrm{mL}$ of FluA NP, respectively. Strips 5 and 6 compare scFvOmpA $\mathrm{TM}_{\text {TM }}$ particles incubated with $5000 \mathrm{ng} / \mathrm{mL}$ FluA NP and RSV NP, respectively. Strip 7 shows ${ }^{*} \mathrm{OmpA}_{\mathrm{TM}}$ conjugated particles incubated with $5000 \mathrm{ng} / \mathrm{mL}$ FluA NP. All proteinAuNP conjugates were made with both protein and thioAlkylPEG filler.

Assembly of $\mathrm{GGzOmpA}_{\mathrm{TM}}$-AuNP and subsequent binding of a monoclonal antibody were followed by DLS (Figure 4A and Figure 4C). This showed a surface layer thickness of 10.1 \pm 0.53 and $12.13 \pm 0.68 \mathrm{~nm}$ after addition of $\mathrm{GGzOmpA}_{\mathrm{TM}}$ and the thioAlkylPEG filler, respectively, confirming that infilling of the surface may encourage a more perpendicular protein orientation. This observation is consistent with previous AFM and neutron reflection studies of engineered $\mathrm{OmpA}_{\mathrm{TM}}$ arrays on planar gold surfaces ${ }^{16,17}$ which showed an increase in orientation and stability after filler assembly. The protein layer thickness and antibody binding function were thus indicative of ordered protein assembly where the antibody binding domains are displayed away from the particle surface. ${ }^{20}$ Incubation with a mAb formed a combined thickness of 19.26 $\pm 2.04 \mathrm{~nm}$ protein on the AuNP surface, confirming that the B-domains were free to bind antibody. The increase in standard error from \pm 0.68 to $\pm 2.04 \mathrm{~nm}$ in the DLS measurements after $\mathrm{mAb}$ binding was suggestive of a less homogeneous population of particles, possibly due to differing amounts of $\mathrm{mAb}$ bound. Antibody binding was specific to $\mathrm{GGzOmpA}_{\mathrm{TM}}$ coated AuNPs with wild type and cysOmpA $\mathrm{A}_{\mathrm{TM}}$ particles showing low levels of nonspecific binding (Figure 4B).

Surface Assembly of Antibody Domains for Influenza Detection. The most common application of conjugated AuNPs is in diagnostic tests where they are used to detect a number of different antigens such as proteins and DNA. ${ }^{36}$ Therefore, the ability of the modular $\mathrm{OmpA}_{\mathrm{TM}}$ system, assembled on AuNPs, to detect a clinical antigen was tested. For this we used a different $\mathrm{OmpA}_{\mathrm{TM}}$ fusion protein which contained at its $\mathrm{N}$-terminus an antigen binding domain derived from an antibody. Since the antigen binding or complementarity-determining regions (CDRs) of antibodies consist of two separate proteins, engineered versions called single chain variable fragments $(\mathrm{scFv})$ have been developed which combine the recognition domains of immunoglobulins into a single polypeptide chain. These can be derived from known antibodies, or novel functions can be developed using combinatorial selection procedures to select the scFv of choice from a random library. ${ }^{37}$ This protein $\left(\mathrm{scFvOmpA}_{\mathrm{TM}}\right)$ consisted of a bespoke single chain variable fragment ( $\mathrm{scFv}$ domain), selected to bind influenza A nucleoprotein (FluA NP) using a bacterial retained display platform and affinity selection techniques, ${ }^{38}$ fused to the N-terminus of circularly permuted cysOmpA $\mathrm{T}_{\mathrm{TM}}$ via an $\alpha$-helical linker domain. This engineered protein eliminates the need for both animal derived antibodies and immobilization chemistries, allowing a highly selective AuNP surface to be manufactured using a single recombinant protein easily manufactured by bacterial fermentation. A second protein $\left(* \mathrm{OmpA}_{\mathrm{TM}}\right)$, which consisted of just the cysOmpA $\mathrm{TM}_{\mathrm{TM}}$ and $\alpha$ helical linker domains, was used as a negative control (Figure $5 \mathrm{~A}$ and Figure $5 \mathrm{~B}$ ). Binding of recombinant FluA NP to $s c F v O m p A_{\mathrm{TM}}$ conjugated particles was observed by UV-vis spectroscopy as a red shift in the LSPR peak and DLS as a large increase in the particle size (Figure 5C and Figure 5D). TEM images of $\mathrm{scFvOmpA}_{\mathrm{TM}}$ particles after incubation with FluA NP revealed large objects bound to the surface of the particles that were not present before antigen addition (Figure 5E and Figure 5F). These are larger than expected for NP; however the monomeric species 
exists in equilibrium with trimers ${ }^{39}$ which at $150 \mathrm{kDa}$ approximate to the structures seen here. This flu NP quaternary structure also explains both the cross-linking of AuNP by the flu antigen observed in EM (Figure $5 \mathrm{~F}$ ) and, by forming multi AuNP-FluA NP complexes via multivalent interactions, the strong binding response seen by spectroscopy and DLS. This effect has also been exploited in AuNP LSPR based assays of intact flu virus where binding to the hemagglutinin proteins on the viral surface brings many AuNP into close proximity. ${ }^{40}$ Here, samples of the complexes were observed by TEM with FluA NP apparently bridging

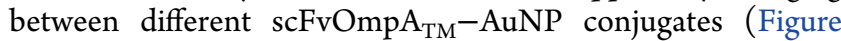
$5 \mathrm{~F})$. Detection of FluA NP was thus robust and specific. Control particles conjugated with $* \mathrm{OmpA}_{\mathrm{TM}}$, the negative control protein, did not show any FluA NP binding by either UV-vis spectroscopy or DLS. Finally, FluA NP binding to scFvOmpA $\mathrm{TM}_{\mathrm{TM}}$-AuNP conjugates was tested using a lateral flow assay (LFA). LFAs are widely used in diagnostics and comprise a porous membrane, commonly nitrocellulose, to which antibodies are immobilized in defined lines. ${ }^{21}$ Samples suspected of containing the antigen are mixed with visible particles, usually AuNPs or latex beads that have been conjugated with a second antibody, which recognizes a secondary site on the antigen. This solution is allowed to flow along the strip, with any bound antigen forming a crosslink between the particle and the immobilized antibody, leading to the formation of a characteristic colored line. A second antibody line on the strip acts as a control, binding to the antibody on the particle surface. A prototype lateral flow assay which used $\alpha$-FluA NP and $\alpha$-human IgG antibodies, as the capture and control lines respectively, could detect a minimum of $500 \mathrm{ng} / \mathrm{mL}$ FluA NP when incubated with $\mathrm{scFvOmpA}_{\mathrm{TM}}$ coated particles (Figure 5G). This is comparable sensitivity to commercially available anti-NP antibodies used in diagnostic assays. ${ }^{41}$ Detection was specific to FluA NP with no capture line observed for $\mathrm{scFvOmpA}_{\mathrm{TM}}$ particles incubated with recombinant respiratory syncytial virus nucleoprotein (RSV NP) (Figure 5G). Detection was also accurate and discriminatory since all samples containing FluA NP were positive and no capture or control binding was observed for AuNPs conjugated with the $* \mathrm{OmpA}_{\mathrm{TM}}$ control protein after incubation with FluA NP (Figure $5 \mathrm{G}$ ). Comparison of the detection limits with other methods is somewhat difficult as they are not always directly comparable. It is also difficult to find primary data for the detection limits of commercial LFAs. The detection limit presented here is comparable to a lateral flow assay using silica nanoparticles ${ }^{42}$ and a double antibody sandwich enzyme-linked immunosorbent ELISA assay. ${ }^{43}$ However, more complex detection methods, such as twophoton fluorescence excitation, have been able to detect nucleoprotein concentrations down to $50 \mathrm{ng} / \mathrm{mL}{ }^{44}$ The experimental conditions used here, while not using patient samples, are comparable to the clinical situation where the tests use diluted washes of nasal swabs. These samples are free of the complications of blood samples and, compared to tests for other biomarkers, contain relatively large amounts of shed virions and viral proteins.

\section{CONCLUSION}

The work presented here describes the simple creation of gold nanoparticles decorated with functional protein domains suitable for diagnostic applications. The addition of a single cysteine residue in a periplasmic loop of $\mathrm{OmpA}_{\mathrm{TM}}$ plays an important role in its assembly on the surface of AuNPs. Although significant amounts of WT protein bind to AuNP, the addition of the cys residue leads to larger amounts of bound protein, greater stability (Figure 1), more efficient assembly of the membrane mimicking thioAlkylPEG layer (Figure 2), and improved protein orientation, consistent with previous studies. ${ }^{15-17,20} \mathrm{We}$ then used two different engineered multidomain $\mathrm{OmpA}_{\mathrm{TM}}$ protein chimeras. GGzOm$\mathrm{pA}_{\mathrm{TM}}$, which contains antibody binding domains, was shown to form ordered protein arrays on AuNPs with the functional Gdomains displayed away from the surface and able to display monoclonal IgG antibodies. Next we fused a single domain antibody, which recognizes the influenza antigen FluA NP, to $\mathrm{OmpA}_{\mathrm{TM}}\left(\mathrm{scFv}-\mathrm{OmpA}_{\mathrm{TM}}\right)$. FluA $\mathrm{NP}$ is an important diagnostic antigen used in the detection of influenza infections. Nanoparticles decorated with anti-FluA NP scFv-OmpA $A_{\mathrm{TM}}$ were used to detect FluA NP using UV-vis spectroscopy, dynamic light scattering, and electron microscopy. Furthermore, it was used in a lateral flow assay (Figure 5) as proof of concept for using self-assembled engineered membrane proteins in a clinically relevant diagnostic test. By fusing recombinant single chain antibodies with a self-assembling scaffold protein, this approach removes the need for complex and inefficient conjugation of animal derived antibodies. It has the scope to detect a wide variety of antigens with antibodylike specificity while being economically produced on a large scale by bacterial fermentation. Additional applications could include gold labeling of cellular or engineered (FLAG) antigens in electron microscopy.

\section{MATERIALS AND METHODS}

Materials. Gold nanoparticles were purchased from BBI Solutions (Cardiff, U.K.). Antibodies were purchased from HyTest (Turku, Finland) and Abcam (Cambridge, U.K.). Molecular biology and protein purification materials were purchased from Invitrogen, Generon, and GE Healthcare (U.K.). All other materials were purchased from Sigma-Aldrich unless otherwise stated.

Protein Production and Purification. wtOmpA $\mathrm{Am}_{\mathrm{TM}}$ and $\mathrm{cysOmpA}_{\mathrm{TM}}$ were expressed, purified, and refolded from inclusion bodies as described previously for OmpAZ. ${ }^{15} \mathrm{GGzOmpA}_{\mathrm{TM}}$ was expressed, purified, and refolded as described previously. ${ }^{20}$ $\mathrm{scFvOmpA}_{\mathrm{TM}}$ was expressed, purified, and refolded as described for $\mathrm{GGzOmpA}_{\mathrm{TM}}$. The bespoke scFv domain was purchased from Affinity Bio (Scoresby, Australia). ${ }^{*} \mathrm{OmpA} \mathrm{TM}_{\mathrm{TM}}$ was also expressed, purified, and refolded as described for $\mathrm{GGzOmpA}_{\mathrm{TM}}$. Recombinant influenza $\mathrm{A}$ nucleoprotein expression and purification were carried out as described previously. ${ }^{20}$ Recombinant respiratory syncytial virus nucleoprotein expression and purification were carried out as for influenza A nucleoprotein.

Equilibrium Binding Measurements. wtOmpA $\mathrm{A}_{\mathrm{TM}}$ and cysOm$\mathrm{pA}_{\mathrm{TM}}$ were buffer exchanged into DDM buffer $(0.5 \% \mathrm{w} / \mathrm{v} n$-dodecyl $\beta$-D-maltoside, $10 \mathrm{mM}$ Tris- $\mathrm{HCl}, \mathrm{pH} 8)$ using a PD10 desalting column (GE Healthcare). The resulting protein solution was incubated in $5 \mathrm{mM}$ TCEP (tris(2-carboxyethyl)phosphine) for 30 min before use. $20 \mathrm{~nm}$ AuNPs at $\mathrm{OD}_{525 \mathrm{~nm}}=1$ were mixed with protein at concentrations between 0.016 and $0.8 \mu \mathrm{M}$ before overnight incubation at room temperature. UV-vis spectra were acquired with a Cary 4E spectrophotometer between 400 and $800 \mathrm{~nm}$. The barycentric mean wavelength $\left(\lambda_{\mathrm{m}}\right)$ was calculated between 500 and $600 \mathrm{~nm}$ using the following equation: ${ }^{45}$

$$
\lambda_{\mathrm{m}}=\frac{\sum I(\lambda) \lambda}{\sum I(\lambda)}
$$

where $I(\lambda)$ is the absorbance at wavelength $\lambda$. The shift $\left(\Delta \lambda_{\mathrm{m}}\right)$ was calculated as the difference from the $\lambda_{\mathrm{m}}$ of nonfunctionalized AuNPs. 
Fluorescence Spectroscopy. Overnight assembly of wtOmpA $\mathrm{AM}_{\mathrm{TM}}$ and cysOmpA $\mathrm{TM}_{\mathrm{TM}}-\mathrm{AuNP}$ conjugates was carried out as for the equilibrium binding experiments with protein concentrations between 0.08 and $0.8 \mu \mathrm{M}$. Before carrying out fluorescence measurements of protein concentration, the protein-AuNP conjugates were removed by centrifugation at $20000 \mathrm{~g}$ for $10 \mathrm{~min}$. Protein binding was calculated by measuring the residual protein concentration using the intensity of the tryptophan fluorescence of the supernatant. Fluorescence spectra were acquired using a Cary Eclipse fluorescence spectrophotometer using $5 \mathrm{~mm}$ path length quartz cuvettes (Hellma 111.057). Excitation was at $280 \mathrm{~nm}$ and emission scanned between 300 and $450 \mathrm{~nm}$. Total fluorescence was calculated by integrating the intensities between 300 and $400 \mathrm{~nm}$ for each sample and the protein concentration calculated from a calibration curve made using protein standards between 0.0125 and $1 \mu \mathrm{M}$.

Protein-AuNP Conjugate Stability. Overnight preparation of wtOmpA $\mathrm{T}_{\mathrm{TM}}$ and cysOmpA $\mathrm{TM}_{\mathrm{TM}}-\mathrm{AuNP}$ conjugates was carried out as for the equilibrium binding experiments with a protein concentration of $0.8 \mu \mathrm{M}$. Protein-AuNP conjugates at $\mathrm{OD}_{525 \mathrm{~nm}}=1$ were mixed with $\mathrm{NaBH}_{4}$ at concentrations between 0.05 and $1.5 \mathrm{mM}$ before incubating at room temperature for $3 \mathrm{~h}$. UV-vis spectra were acquired with the Cary 4E spectrophotometer for the protein-AuNP conjugates before and after $\mathrm{NaBH}_{4}$ addition. Stability was measured as the ratio of the shift in the $\lambda_{\mathrm{m}}$ before and after $\mathrm{NaBH}_{4}$ addition.

Agarose Gel Electrophoresis. Protein-AuNP conjugates were made by mixing $20 \mathrm{~nm}$ AuNPs at $\mathrm{OD}_{525 \mathrm{~nm}}=10$ with $8 \mu \mathrm{M}$ protein before overnight incubation. Coassembly of the 1-mercaptoundecyl11-hexa(ethylene glycol) filler molecule was carried out $30 \mathrm{~min}$ after incubation with the protein by mixing the protein-AuNP conjugates with $8 \mu \mathrm{M}$ filler and incubating overnight. Electrophoresis was carried out using $1 \%$ agarose gels made with TB buffer $(90 \mathrm{mM}$ Tris- $\mathrm{HCl}, 90$ $\mathrm{mM}$ boric acid) and run in TB buffer supplemented with $0.025 \%$ Tween 20. $20 \mu \mathrm{L}$ of AuNP sample was mixed with $5 \mu \mathrm{L}$ of loading buffer (TB buffer supplemented with 30\% w/v glycerol and $0.05 \%$ Tween 20) before loading on the gel and running for $70 \mathrm{~min}$ at $100 \mathrm{~V}$ in an ice bath. Gels were imaged immediately using a Bio-Rad Gel Doc XR+.

Transmission Electron Microscopy. GGzOmpA $\mathrm{TM}_{\mathrm{TM}}-\mathrm{AuNP}$ conjugates were excised from agarose gel bands and extracted overnight into Nanopure water. Samples were deposited on to 200 mesh, carbon coated, glow discharged grids using the single droplet method. ${ }^{46}$ Negative staining was carried out with a $2 \%$ uranyl acetate solution. All samples were imaged using a Philips CM100 TEM with a CompuStage. The resulting images were processed using the Image software $(\mathrm{NIH})$.

Dynamic Light Scattering. DLS measurements were carried out in a $45 \mu \mathrm{L}$ cuvette (Hellma) with a Malvern Zetasizer Nano S. Residual protein was removed by centrifugation of the protein-AuNP conjugates at $16900 \mathrm{~g}$ and resuspension in Nanopure water. For antibody binding experiments, protein conjugated particles were mixed with $1 \mu \mathrm{M}$ monoclonal antivinculin antibody and incubated for $10 \mathrm{~min}$ before centrifugation at $16900 \mathrm{~g}$ and resuspension in Nanopure water.

FluA NP Binding Experiments. $\mathrm{scFvOmpA}_{\mathrm{TM}}-\mathrm{AuNP}$ conjugates were made with protein and filler concentrations of $0.8 \mu \mathrm{M}$ using the same method as for $\mathrm{cysOmpA}_{\mathrm{TM}}$. Residual protein was removed by centrifugation and resuspension in Nanopure water. The resulting $\mathrm{scFvOmpA}_{\mathrm{TM}}-\mathrm{AuNP}$ conjugates, at $\mathrm{OD}_{525 \mathrm{~nm}}=1$, were mixed with $150 \mathrm{nM}$ of FluA NP and incubated for $10 \mathrm{~min}$ before residual protein was removed by centrifugation and resuspension in Nanopure water. UV-vis spectroscopy, DLS, and TEM were then carried out on the protein-AuNP conjugates before and after FluA NP incubation.

Analytical Ultracentrifugation (AUC). Sedimentation velocity (SV) experiments were carried out with a Beckman Coulter Optima XL-I analytical ultracentrifuge (Palo Alto, CA, USA) using both absorbance at $530 \mathrm{~nm}$ and interference optics at a rotation speed of $5000 \mathrm{rpm}$ and experimental temperature of $20^{\circ} \mathrm{C}$. The AuNPs were diluted in water to a final concentration of $\mathrm{OD}_{530 \mathrm{~nm}}=1.5$ with a path length of $1 \mathrm{~cm}$. A sample volume of $400 \mu \mathrm{L}$ was used. Sedimentation velocity profiles were analyzed using both $1 \mathrm{D}$ size-distribution $c(s)^{32,32}$ and $2 \mathrm{D}$ distribution $c\left(s, f / f_{0}\right)^{33,33}$ models implemented in the program SEDFIT. ${ }^{47,44}$ Each peak on the distribution plot was integrated in order to obtain the weight-averaged values for sedimentation coefficient. In brief, sedimentation of the material is described by the Svedberg equation as follows: ${ }^{48,45}$

$$
M=\frac{s R T}{D\left(1-\bar{v}_{\text {particle }} \rho_{\text {solvent }}\right)}
$$

where $M$ is the particle's molecular mass, $s$ is its sedimentation coefficient, $D$ is the diffusion coefficient, $\bar{v}_{\text {particle }}$ is the partial specific volume of the sedimenting particle, $\rho_{\text {solvent }}$ is the density of the solvent, $T$ is the absolute temperature, and $R$ is the ideal gas constant.

The partial specific volume can be represented in terms of the particle's density, $\rho_{\text {particle, }}$ as

$$
\bar{v}=1 / \rho_{\text {particle }}
$$

The density of the particle can, in turn, be expressed as a function of its hydrodynamic radius, $R_{\mathrm{h}}$, and sedimentation coefficient, $s$, by ${ }^{35,49,35,46}$

$$
\rho_{\text {particle }}=\rho_{\text {solvent }}+\frac{18 \eta_{\text {solvent }} s}{\left(2 R_{\mathrm{h}}\right)^{2}}
$$

where $\rho_{\text {solvent }}$ is the density of the solvent and $\eta_{\text {solvent }}$ is its viscosity.

Lateral Flow. Lateral flow strips were made from nitrocellulose membrane $(4 \mathrm{~cm} \times 30 \mathrm{~cm})$ with capture and control antibody lines deposited by hand using a pipet tip at $0.5 \mathrm{mg} / \mathrm{mL}$ in binding buffer $\left(10 \mathrm{mM} \mathrm{NaCO}_{3}, \mathrm{pH} 9.5\right)$. The strips were blocked overnight with $2 \%$ w/v BSA at $4{ }^{\circ} \mathrm{C}$ and cut into $4 \mathrm{~cm} \times 0.5 \mathrm{~cm}$ segments before use. An amount of $7.5 \mu \mathrm{L}$ of protein-AuNP conjugate samples at $\mathrm{OD}_{525 \mathrm{~nm}}=$ 10 was mixed with $7.5 \mu \mathrm{L}$ of antigen solution and incubated for $5 \mathrm{~min}$ before applying to the opposite end of the nitrocellulose strip to the antibody lines. The solution progressed through the membrane via capillary action and the strips were washed 5 times with $20 \mu \mathrm{L}$ of washing buffer ( $50 \mathrm{mM}$ Tris- $\mathrm{HCl}, 150 \mathrm{mM} \mathrm{NaCl}, 0.05 \%$ Tween 20 , $\mathrm{pH} 7.8$ ) before imaging with a digital camera.

\section{ASSOCIATED CONTENT}

\section{Supporting Information}

The Supporting Information is available free of charge on the ACS Publications website at DOI: 10.1021/acsanm.8b00737.

Protein binding kinetics and AUC analysis of the AuNPs (PDF)

\section{AUTHOR INFORMATION}

\section{Corresponding Author}

*E-mail: j.h.lakey@ncl.ac.uk.

ORCID 웅

Jeremy H. Lakey: 0000-0003-4646-9085

\section{Author Contributions}

The manuscript was written through contributions of all authors. All authors have given approval to the final version of the manuscript.

\section{Funding}

This work was supported by a BBSRC Industrial CASE Award to Tim Robson with additional funding from Orla Protein Technologies Ltd. We thank the Wellcome Trust for Equipment Grant 064345.

\section{Notes}

The authors declare no competing financial interest. 


\section{ACKNOWLEDGMENTS}

We thank Dr. Helen Waller for expert technical assistance. We acknowledge the Newcastle University EM Research Services for assistance with the generation of EM images.

\section{ABBREVIATIONS}

AuNP = gold nanoparticle

LSPR = localized surface plasmon resonance

DLS = dynamic light scattering

AUC = analytical ultracentrifugation

$\mathrm{OD}=$ optical density

TEM = transmission electron microscopy

$\mathrm{mAb}=$ monoclonal antibody

$\mathrm{OmpA}_{\mathrm{TM}}=$ transmembrane domain of E. coli outer membrane protein $\mathrm{A}$

cysOmpA $\mathrm{TM}_{\mathrm{TM}}=$ cysteine mutant of $\mathrm{OmpA}_{\mathrm{TM}}$

$\mathrm{GGzOmpA}_{\mathrm{TM}}=\mathrm{N}$ terminal tandem pair of $\mathrm{B}$ domains from protein $G$ and $Z$ domain from protein $A$ fused to a cysOmpA $A_{T M}$ scaffold

$\mathrm{scFvOmpA}_{\mathrm{TM}}=\mathrm{N}$-terminal single chain variable fragment domain fused to an ${ }^{*} \mathrm{OmpA}_{\mathrm{TM}}$ scaffold

$* \mathrm{OmpA}_{\mathrm{TM}}=\alpha$ helical linker domain fused to cysOmpA $\mathrm{TM}_{\mathrm{TM}}$ FluA NP = influenza A nucleoprotein

\section{REFERENCES}

(1) Zhou, W.; Gao, X.; Liu, D.; Chen, X. Gold Nanoparticles for In Vitro Diagnostics. Chem. Rev. 2015, 115, 10575-10636.

(2) Vigderman, L.; Zubarev, E. R. Therapeutic Platforms Based on Gold Nanoparticles and Their Covalent Conjugates with Drug Molecules. Adv. Drug Delivery Rev. 2013, 65, 663-676.

(3) Frens, G. Controlled Nucleation for the Regulation of the Particle Size in Monodisperse Gold Suspensions. Nature, Phys. Sci. 1973, 241, 20-22.

(4) Orlando, A.; Colombo, M.; Prosperi, D.; Corsi, F.; Panariti, A.; Rivolta, I.; Masserini, M.; Cazzaniga, E. Evaluation of Gold Nanoparticles Biocompatibility: A Multiparametric Study on Cultured Endothelial Cells and Macrophages. J. Nanopart. Res. 2016, 18, 58.

(5) Willets, K. A.; Van Duyne, R. P. Localized Surface Plasmon Resonance Spectroscopy and Sensing. Annu. Rev. Phys. Chem. 2007, 58, 267-297.

(6) Huang, X.; El-Sayed, M. A. Gold Nanoparticles: Optical Properties and Implementations in Cancer Diagnosis and Photothermal Therapy. J. Adv. Res. 2010, 1, 13-28.

(7) Ke, H.; Wang, J.; Dai, Z.; Jin, Y.; Qu, E.; Xing, Z.; Guo, C.; Yue, X.; Liu, J. Gold-Nanoshelled Microcapsules: A Theranostic Agent for Ultrasound Contrast Imaging and Photothermal Therapy. Angew. Chem., Int. Ed. 2011, 50, 3017-3021.

(8) Kennedy, L. C.; Bickford, L. R.; Lewinski, N. A.; Coughlin, A. J.; Hu, Y.; Day, E. S.; West, J. L.; Drezek, R. A. A New Era for Cancer Treatment: Gold-Nanoparticle-Mediated Thermal Therapies. Small 2011, 7, 169-183.

(9) Puertas, S.; Moros, M.; Fernández-Pacheco, R.; Ibarra, M. R.; Grazú, V.; de la Fuente, J. M. Designing Novel Nano-Immunoassays: Antibody Orientation versus Sensitivity. J. Phys. D: Appl. Phys. 2010, 43, 474012 .

(10) Liu, F.; Wang, L.; Wang, H.; Yuan, L.; Li, J.; Brash, J. L.; Chen, H. Modulating the Activity of Protein Conjugated to Gold Nanoparticles by Site-Directed Orientation and Surface Density of Bound Protein. ACS Appl. Mater. Interfaces 2015, 7, 3717-3724.

(11) Lee, K.; Conboy, M.; Park, H. M.; Jiang, F.; Kim, H. J.; Dewitt, M. A.; Mackley, V. A.; Chang, K.; Rao, A.; Skinner, C.; et al. Nanoparticle Delivery of Cas9 Ribonucleoprotein and Donor DNA in Vivo Induces Homology-Directed DNA Repair. Nat. Biomed. Eng. 2017, 1, 889-901.
(12) Duncan, B.; Kim, C.; Rotello, V. M. Gold Nanoparticle Platforms as Drug and Biomacromolecule Delivery Systems. J. Controlled Release 2010, 148, 122-127.

(13) Bartczak, D.; Kanaras, A. G. Preparation of Peptide-Functionalized Gold Nanoparticles Using One Pot EDC/Sulfo-NHS Coupling. Langmuir 2011, 27, 10119-10123.

(14) Welch, N. G.; Scoble, J. A.; Muir, B. W.; Pigram, P. J. Orientation and Characterization of Immobilized Antibodies for Improved Immunoassays (Review). Biointerphases 2017, 12, 02 D301.

(15) Le Brun, A. P.; Holt, S. A.; Shah, D. S.; Majkrzak, C. F.; Lakey, J. H. Monitoring the Assembly of Antibody-Binding Membrane Protein Arrays Using Polarised Neutron Reflection. Eur. Biophys. J. 2008, 37, 639-645.

(16) Cisneros, D. A.; Muller, D. J.; Daud, S. M.; Lakey, J. H. An Approach To Prepare Membrane Proteins for Single-Molecule Imaging. Angew. Chem., Int. Ed. 2006, 45, 3252-3256.

(17) Le Brun, A. P.; Holt, S. A.; Shah, D. S. H.; Majkrzak, C. F.; Lakey, J. H. The Structural Orientation of Antibody Layers Bound to Engineered Biosensor Surfaces. Biomaterials 2011, 32, 3303-3311.

(18) Nilsson, B.; Moks, T.; Jansson, B.; Abrahmsén, L.; Elmblad, A.; Holmgren, E.; Henrichson, C.; Jones, T. A.; Uhlén, M. A Synthetic IgG-Binding Domain Based on Staphylococcal Protein A. Protein Eng., Des. Sel. 1987, 1, 107-113.

(19) Derrick, J. P.; Wigley, D. B. The Third IgG-Binding Domain from Streptococcal Protein G. J. Mol. Biol. 1994, 243, 906-918.

(20) Le Brun, A. P.; Soliakov, A.; Shah, D. S. H.; Holt, S. A.; McGill, A.; Lakey, J. H. Engineered Self-Assembling Monolayers for Label Free Detection of Influenza Nucleoprotein. Biomed. Microdevices 2015, 17, 1-10.

(21) Posthuma-Trumpie, G. A.; Korf, J.; van Amerongen, A. Lateral Flow (Immuno)Assay: Its Strengths, Weaknesses, Opportunities and Threats. A Literature Survey. Anal. Bioanal. Chem. 2009, 393, 569582.

(22) Boulos, S. P.; Davis, T. A.; Yang, J. A.; Lohse, S. E.; Alkilany, A. M.; Holland, L. A.; Murphy, C. J. Nanoparticle-Protein Interactions: A Thermodynamic and Kinetic Study of the Adsorption of Bovine Serum Albumin to Gold Nanoparticle Surfaces. Langmuir 2013, 29, 14984-14996.

(23) Ceccon, A.; Tugarinov, V.; Bax, A.; Clore, G. M. Global Dynamics and Exchange Kinetics of a Protein on the Surface of Nanoparticles Revealed by Relaxation-Based Solution NMR Spectroscopy. J. Am. Chem. Soc. 2016, 138, 5789-5792.

(24) Spinozzi, F.; Ceccone, G.; Moretti, P.; Campanella, G.; Ferrero, C.; Combet, S.; Ojea-Jimenez, I.; Ghigna, P. Structural and Thermodynamic Properties of Nanoparticle-Protein Complexes: A Combined SAXS and SANS Study. Langmuir 2017, 33, 2248-2256.

(25) Wang, A.; Vangala, K.; Vo, T.; Zhang, D.; Fitzkee, N. C. A Three-Step Model for Protein-Gold Nanoparticle Adsorption. J. Phys. Chem. C 2014, 118, 8134-8142.

(26) Lin, W.; Insley, T.; Tuttle, M. D.; Zhu, L.; Berthold, D. A.; Král, P.; Rienstra, C. M.; Murphy, C. J. Control of Protein Orientation on Gold Nanoparticles. J. Phys. Chem. C 2015, 119, 21035-21043.

(27) Liu, Y.; Liu, Y.; Mernaugh, R. L.; Zeng, X. Single Chain Fragment Variable Recombinant Antibody Functionalized Gold Nanoparticles for a Highly Sensitive Colorimetric Immunoassay. Biosens. Bioelectron. 2009, 24, 2853-2857.

(28) Farris, L. R.; Wu, N.; Wang, W.; Clarizia, L.-J. A.; Wang, X.; McDonald, M. J. Immuno-Interferometric Sensor for the Detection of Influenza A Nucleoprotein. Anal. Bioanal. Chem. 2010, 396, 667-674.

(29) Ansar, S. M.; Ameer, F. S.; Hu, W.; Zou, S.; Pittman, C. U.; Zhang, D. Removal of Molecular Adsorbates on Gold Nanoparticles Using Sodium Borohydride in Water. Nano Lett. 2013, 13, 12261229.

(30) Wang, A.; Perera, Y. R.; Davidson, M. B.; Fitzkee, N. C. Electrostatic Interactions and Protein Competition Reveal a Dynamic Surface in Gold Nanoparticle-Protein Adsorption. J. Phys. Chem. C 2016, 120, 24231-24239.

(31) Aldeek, F.; Safi, M.; Zhan, N.; Palui, G.; Mattoussi, H. Understanding the Self-Assembly of Proteins onto Gold Nano- 
particles and Quantum Dots Driven by Metal-Histidine Coordination. ACS Nano 2013, 7, 10197-10210.

(32) Schuck, P. Size-Distribution Analysis of Macromolecules by Sedimentation Velocity Ultracentrifugation and Lamm Equation Modeling. Biophys. J. 2000, 78, 1606-1619.

(33) Brown, P. H.; Schuck, P. Macromolecular Size-and-Shape Distributions by Sedimentation Velocity Analytical Ultracentrifugation. Biophys. J. 2006, 90, 4651-4661.

(34) Bekdemir, A.; Stellacci, F. A Centrifugation-Based Physicochemical Characterization Method for the Interaction between Proteins and Nanoparticles. Nat. Commun. 2016, 7, 13121.

(35) Carney, R. P.; Kim, J. Y.; Qian, H.; Jin, R.; Mehenni, H.; Stellacci, F.; Bakr, O. M. Determination of Nanoparticle Size Distribution Together with Density or Molecular Weight by 2D Analytical Ultracentrifugation. Nat. Commun. 2011, 2, 335.

(36) Quesada-González, D.; Merkoçi, A. Nanoparticle-Based Lateral Flow Biosensors. Biosens. Bioelectron. 2015, 73, 47-63.

(37) Hairul Bahara, N. H.; Tye, G. J.; Choong, Y. S.; Ong, E. B. B.; Ismail, A.; Lim, T. S. Phage Display Antibodies for Diagnostic Applications. Biologicals 2013, 41, 209-216.

(38) Beasley, M. D.; Niven, K. P.; Winnall, W. R.; Kiefel, B. R. Bacterial Cytoplasmic Display Platform Retained Display (ReD) Identifies Stable Human Germline Antibody Frameworks. Biotechnol. J. 2015, 10, 783-789.

(39) Chenavas, S.; Estrozi, L. F.; Slama-Schwok, A.; Delmas, B.; Di Primo, C.; Baudin, F.; Li, X.; Crépin, T.; Ruigrok, R. W. H. Monomeric Nucleoprotein of Influenza A Virus. PLoS Pathog. 2013, 9, e1003275.

(40) Liu, Y.; Zhang, L.; Wei, W.; Zhao, H.; Zhou, Z.; Zhang, Y.; Liu, S. Colorimetric Detection of Influenza A Virus Using AntibodyFunctionalized Gold Nanoparticles. Analyst 2015, 140, 3989-3995.

(41) Phuong, N. H.; Kwak, C.; Heo, C.-K.; Cho, E. W.; Yang, J.; Poo, H. Development and Characterization of Monoclonal Antibodies against Nucleoprotein for Diagnosis of Influenza A Virus. J. Microbiol. Biotechnol. 2018, 28, 809-815.

(42) Bamrungsap, S.; Apiwat, C.; Chantima, W.; Dharakul, T.; Wiriyachaiporn, N. Rapid and Sensitive Lateral Flow Immunoassay for Influenza Antigen Using Fluorescently-Doped Silica Nanoparticles. Microchim. Acta 2014, 181, 223-230.

(43) Siebinga, J. T.; de Boer, G. F. Influenza A Viral Nucleoprotein Detection in Isolates from Human and Various Animal Species. Arch. Virol. 1988, 100, 75-87.

(44) Koskinen, J. O.; Vainionpää, R.; Meltola, N. J.; Soukka, J.; Hänninen, P. E.; Soini, A. E. Rapid Method for Detection of Influenza A and B Virus Antigens by Use of a Two-Photon Excitation Assay Technique and Dry-Chemistry Reagents. J. Clin. Microbiol. 2007, 45, $3581-3588$.

(45) Chalton, D. A.; Lakey, J. H. Simple Detection of Protein Soft Structure Changes. Anal. Chem. 2010, 82 (7), 3073-3076.

(46) Harris, R. Negative Staining and Cryoelectron Microscopy, 2nd ed.; Bios Scientific, 1997.

(47) Schuck, P. Sedimentation Analysis of Noninteracting and SelfAssociating Solutes Using Numerical Solutions to the Lamm Equation. Biophys. J. 1998, 75 (3), 1503-1512.

(48) Lebowitz, J.; Lewis, M. S.; Schuck, P. Modern Analytical Ultracentrifugation in Protein Science: A Tutorial Review. Protein Sci. Publ. Protein Soc. 2002, 11 (9), 2067-2079.

(49) Mächtle, W.; Borger, L. Analytical Ultracentrifugation of Polymers and Nanoparticles; Springer, 2006. 